\title{
Immunohistochemical Localisation of PDE5 in Rat Lung during Pre- and Postnatal Development
}

\author{
Angela Scipioni, ${ }^{1}$ Mauro Giorgi, ${ }^{2}$ Valeria Nuccetelli, ${ }^{2}$ and Stefania Stefanini ${ }^{1}$ \\ ${ }^{1}$ Department of Cellular and Developmental Biology, Sapienza University of Rome, Piazzale Aldo Moro 5, 00185 Rome, Italy \\ ${ }^{2}$ Department of Basic and Applied Biology, University of L'Aquila, Via Vetoio 10, 67010 L'Aquila, Italy
}

Correspondence should be addressed to Mauro Giorgi, mauro.giorgi@univaq.it

Received 31 March 2009; Accepted 18 June 2009

Recommended by Richard Tucker

In mammalian lung, at the transition to extrauterine life, NO/cGMP signal transduction system is known to play crucial roles in the regulation of vascular resistance and is supposed to act in angiogenesis. PDE5, which is the most abundant cGMP metabolizing enzyme within the lung, is highly expressed in the perinatal period, but its localisation in the different pulmonary cells is still poorly known. In our research, PDE5 immunohistochemical distribution was investigated in foetal and neonatal rat lung. The highest expression of PDE5 was found in cells randomly located in the stroma; in newborns, in particular, many cells in the intersaccular walls were heavily labelled, while much lower staining levels were shown by smooth myocytes belonging to vessels and airways. On the basis of their immunoreactivity for $\alpha$-SM actin and/or desmin, most of the heavily PDE5-positive cells were identified as interstitial myofibroblasts and transitional pericytes, while only a few were interpreted as interstitial lipofibroblasts.

Copyright (C) 2009 Angela Scipioni et al. This is an open access article distributed under the Creative Commons Attribution License, which permits unrestricted use, distribution, and reproduction in any medium, provided the original work is properly cited.

\section{Introduction}

In mammals, pulmonary vascular resistance is known to be modulated by cGMP, which induces relaxation of vascular smooth muscle through the activation of cGMP-dependent protein kinases. In smooth muscle cells, cGMP is synthesised by nitric oxide- and natriuretic peptide-activated guanylate cyclases, while its degradation occurs through phosphodiesterases. Among the eleven phosphodiesterase families recognised in mammalian tissues [1], cGMP-binding cGMPspecific phosphodiesterase (PDE5) shows particularly strong enzymatic activities in highly vascularized organs, such as the lungs and the spleen [2-4]. Moreover, its mRNA and protein were specifically detected in vascular smooth muscle cells; so that the enzyme is supposed to play a key role in inducing vessel relaxation.

In adult rat lungs, PDE5 is highly concentrated in smooth muscle cells in the medial layer of pulmonary arteries and veins [5] and its expression increases in hypoxia-induced pulmonary hypertension [6]. Moreover, in rodents as well as in humans, PDE5 specific inhibitors such as zaprinast and sildenafil markedly attenuate hypertension itself $[5,7]$; consequently these substances, together with other agents that modulate intracellular cGMP, are considered as promising, safe, and easy-to-administer therapies for pulmonary hypertension [8].

During the perinatal reorganization of the pulmonary vascular bed, when both constitutive endothelial nitric oxide synthase and soluble guanylate cyclase are highly expressed $[9,10]$, alterations in PDE5 activity, protein, and mRNA were described both in ovine and in rodent lungs $[11,12]$. Moreover, increases of soluble guanylate cyclase and PDE5 were found in lambs with pulmonary hypertension [13] and zaprinast and sildenafil were effective in lowering pulmonary vascular resistance of normal and hypertensive ovine foetuses [14-16]. In hyperoxia-exposed rat pups, sildenafil, besides alleviating pulmonary hypertension, interestingly, increased pulmonary capillary density and preserved alveolar growth; preservation of endothelial network during hyperoxia was also found in vitro [17]. It was therefore suggested that the beneficial effects on vascular and alveolar growth might occur through promotion of lung angiogenesis.

Although sildenafil appears as a promising agent for the management of pulmonary hypertension [18], several 
issues need to be addressed before advocating the clinical use of this and others PDE5 inhibitors. In order to evaluate their side effects, the distribution of the enzyme in the organs and in the different cell types inside the organs must be extensively described. Indeed, in many organs, PDE5 was found to be expressed by cell types different from smooth muscle cells, for example, Purkinje cells [19], platelets, epithelia of renal proximal tubules and collecting ducts, as well as pancreatic duct cells [20, 21]. In adult rat lungs, the enzyme was immunolocalised in the smooth muscle of vessels and airways, including the alveolar ducts and openings of the alveoli; its expression was found to accompany the distal muscularization of pulmonary arterioles, pathognomonic of hypoxia-induced pulmonary hypertension [5-22]. In newborn rat lungs, PDE5 mRNA transcripts were detected in the vascular smooth muscle and in the alveolar walls cells [12]. During foetal lung development, while in vivo, both in normal and hypertensive ovine foetuses the enzyme was only detected in the vascular wall [14]; in vitro, on the other hand, a hyperoxia-inducible expression of PDE5 mRNA and protein was shown in foetal pulmonary artery smooth muscle cells [23].

We decided to investigate the PDE5 expression in different cell populations of the developing rat lung, utilising an affinity purified polyclonal antibody, raised against the $\mathrm{N}$ terminal region of bovine PDE5 [21], revealed by either the conventional or the amplified $\mathrm{ABC}$ immunohistochemical procedure [24]. We examined paraffin sections of lung parenchyma from animals at developmental stages comprised between the embryonic day 15.5th and the postnatal day 14th. Moreover, in order to provide a detailed description of the cell populations that specifically express PDE5 inside the intersaccular walls in early postnatal development, we studied possible colocalization of PDE5 with the cytoskeletal markers $\alpha$-smooth muscle actin ( $\alpha$-SMA) and/or desmin.

\section{Material and Methods}

2.1. Animals. Albino Wistar rats (Charles River, Italy) kept at $20-22^{\circ} \mathrm{C}$, with a dark/light cycle of $12 / 12$ hours. Females were placed with males overnight and examined the following morning for the presence of sperm in the vaginal smear; the sperm observation day was considered as the embryonic day 0.5th (E0.5). Animals were housed and handled according to the European Communities Council Directive of November 24th 1986 (86/609/EEC) and to the Italian Health Ministry guidelines.

2.2. Fixation and Tissue Processing. Pregnant rats at gestational age E15.5 and E17.5 were i.p. injected with Farmotal (Amersham Pharmacia Biotech Italia, Cologno Monzese, Milan, Italy) $100 \mathrm{mg} / \mathrm{kg}$ b.w.; the uterus was quickly removed and immersed in Ringer's solution, individual embryos were extracted from the decidua and fixed by immersion in Bouin, for 4 hours at room temperature (RT). Foetal ages were confirmed basing on weight and length. 10 minutes after immersion in fixative, the embryos were cut along the sagittal plane. Rats aging 3, 7 and 14 days (at least four animals for each developmental stage) were i.p. injected with Farmotal $100 \mathrm{mg} / \mathrm{kg}$ b.w. and were endotracheally instilled with $50-80 \mu \mathrm{L}$ of Bouin's or Methacarn's solutions. The dose of fixative was chosen on the basis of preliminary experiments. Trachea was then ligated; lungs were removed and immersed in the same solutions. A few minutes later, lungs were cut in fragments, which were further fixed for 2-4 hours. All specimens were dehydrated, embedded in paraffin, and sectioned $7 \mu \mathrm{m}$ thick; at least three embryos for each gestational age and several randomly chosen lung samples taken from 3, 7, and 14 day-old rats were utilised for immunolocalisation of PDE5 and cytoskeletal markers.

Concerning the immunolocalisation of cytoskeletal proteins, since a stronger labelling was found after Methacarn fixation with respect to Bouin, the identification of cells coexpressing PDE5 and $\alpha$-SMA or PDE5 and desmin was carried out in serial sections obtained from Methacarn-fixed lungs.

\subsection{Anti-PDE5 Antibody Production and Purification. As} previously described in [21], a specific PDE5 antiserum was produced in rabbits using as immunogen a fusion protein containing glutathione S-transferase and a peptide corresponding to the 68-239 amino acid residues of the Nterminal bovine lung PDE5 sequence. After purification by affinity chromatography on a protein A column this antibody was able to immunoprecipitate cGMP-PDE activity from mouse tissues.

The activity recovered in the immunoprecipitate was identified as PDE5 on the basis of its sensitivity to the specific inhibitors zaprinast $\left(\mathrm{IC}_{50} 0.6 \mu \mathrm{M}\right)$ and sildenafil ( $\mathrm{IC}_{50}$ $4 \mathrm{nM}$ ). Moreover, western blotting of the immunoprecipitate showed three specific immunoreactive bands $(100,93$, and $86 \mathrm{kDa}$ ), corresponding to known PDE5 splice variants [25].

2.4. Western Blot Analysis. Lung samples from adult and suckling rats were homogenized in $20 \mathrm{mM}$ Tris- $\mathrm{HCl}$ buffer, $\mathrm{pH}$ 7.2, containing $0.2 \mathrm{mM}$ EGTA, $5 \mathrm{mM}$ mercaptoethanol, $1 \mathrm{mM}$ PMSF, $5 \mathrm{mM} \mathrm{MgCl}_{2}$, and $2 \%(\mathrm{v} / \mathrm{v})$ antiprotease cocktail, using a glass homogenizer (15 strokes, $4^{\circ} \mathrm{C}$ ). Homogenates were centrifuged at $14000 \mathrm{x}$ g for 30 minutes at $4^{\circ} \mathrm{C}$, and pellets were resuspended in the homogenization buffer and centrifuged at $14000 \mathrm{x} \mathrm{g}$ for 30 minutes $\left(4^{\circ} \mathrm{C}\right)$. The first and second supernatants were then pooled and denatured for an SDS-Page run. Protein determination was performed using the procedure of Lowry [26]. SDSpolyacrylamide gel electrophoresis was performed on $10 \%$ slab gels according to Laemmli [27], and proteins were then transferred to nitrocellulose membranes according to Towbin et al. [28]. The blots were incubated for 3 hours at RT with 1:1000 rabbit polyclonal anti-PDE5 and mouse monoclonal antiactin antibodies (Sigma Chemical Co., St. Louis, USA); actin band was used as reference protein in densitometric evaluation. In competition experiments, the incubation medium was supplemented with $10 \mu \mathrm{g} / \mathrm{mL}$ of the PDE5-peptide antigen used to raise PDE5 antibody. 
Alkaline phosphatase-conjugated goat, antirabbit and antimouse IgG were used to reveal immunocomplexes. The bands were then stained with nitro-blue tetrazolium in the presence of 5-bromo-4-chloro-3-indolyl-phosphate. A crude extract of N18TG2 cells, which are known to highly express PDE5 [21], was utilised as a positive control. Densitometric analysis on scanned blots was performed using the NIH ImageJ v1.29 program; the significance of differences was evaluated by means of variance analysis (ANOVA).

2.5. Immunohistochemistry. Freshly deparaffinized sections were treated with $0.3 \% \mathrm{H}_{2} \mathrm{O}_{2}$ in methanol, for 30 minutes at $\mathrm{RT}$, to inactivate endogenous peroxidases; after rehydration they were transferred to PBS containing $0.2 \%$ Triton X-100 and $5 \%$ nonfat dry milk, for 1 hour at RT, and then incubated for 24 hours at $4{ }^{\circ} \mathrm{C}$, in the primary antibodies, diluted in PBS containing $0.1 \%$ Triton X-100 and $2.5 \%$ nonfat dry milk.

Dilutions were: 1:200 rabbit polyclonal anti-PDE5; 1:300 mouse monoclonal antihuman muscle actin (Dako, Carpinteria, CA, USA); 1:800 mouse monoclonal anti- $\alpha$ SMA (Sigma Chemical Co., St. Louis, USA); 1:100 mouse monoclonal antidesmin (Sigma Chemical Co., St. Louis, USA).

For the revelation of immunocomplexes through the conventional $\mathrm{ABC}$ method, sections were sequentially incubated in

(i) 1:200 biotinylated goat antirabbit or rabbit antimouse IgG, for 1 hour at RT,

(ii) avidin-biotin-horseradish peroxidase complex, for 1 hour at RT,

(iii) $0.05 \%$ 3,3'-diaminobenzidine (DAB) in PBS containing $0.01 \mathrm{H}_{2} \mathrm{O}_{2}$ for $2-5$ minutes at $\mathrm{RT}$, in the amplified $\mathrm{ABC}$ procedure the step (ii) was followed by

(i) incubation in biotinylated tyramine, 1:100 diluted in PBS containing $0.01 \mathrm{H}_{2} \mathrm{O}_{2}$ for 10 minutes at RT,

(ii) avidin-biotin-horseradish peroxidase complex, for 30 minutes at RT.

Microwave treatment was carried out incubating freshly rehydrated sections with citrate buffer $\mathrm{pH} 6(10$ minutes at RT, 8 minutes in the microwave oven at $750 \mathrm{~W}$, and 30 minutes at RT).

For negative control, the primary antibody was omitted or substituted with preimmune serum. Moreover, some sections were incubated with the anti-PDE5 antibody preadsorbed (overnight at $4^{\circ} \mathrm{C}$ ) with $150 \mu \mathrm{g} / \mathrm{mL}$ of the PDE5peptide utilised as immunogen [21].

Unstained and haematoxylin counterstained sections were examined in a Zeiss Axioskop2, equipped with a video camera. Representative images were electronically captured; contrast and brightness were adjusted via Adobe Photoshop 6.0.
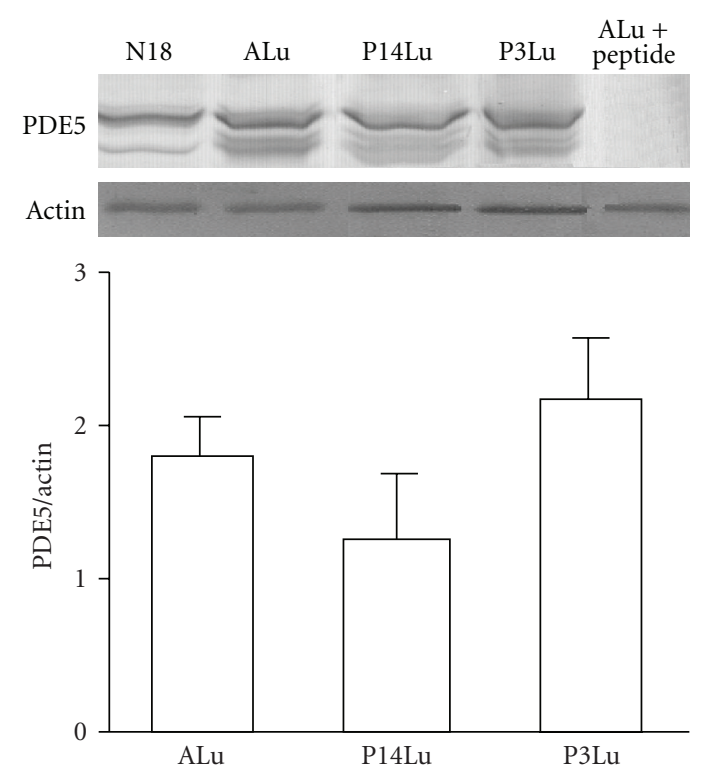

Figure 1: PDE5 expression at different stages of rat lung development. Upper panel: representative western blot analysis of adult lung (ALu), 14 day-old lung (P14Lu), 3 day-old lung (P3Lu), adult lung incubated in presence of PDE5-peptide (ALu+peptide). N18 cell culture (N18) was utilised as standard of PDE5. Each lane was loaded with $50 \mu \mathrm{g}$ of protein. Lower panel: densitometric quantification of immunoreactive PDE5 and actin bands. Data are mean \pm SD of 3 different experiments. Differences were not significant (ANOVA test).

\section{Results}

3.1. Western Blot Analysis. As shown in Figure 1, both lung preparations and neuroblastoma N18TG2 cell extract showed the strong bands at $100 \mathrm{kDa}$, corresponding to the PDE5 main splicing variant; the less intense bands, detected at lower molecular masses ( 93 and $86 \mathrm{kDa}$ ), were identified as corresponding to other known splice variants [25]. The absence of reactivity shown by the sample incubated in peptide-supplemented medium confirmed the antibody specificity. All these results are in agreement with previous data obtained in experiments on mice [21]. Quantitative examination, carried out using actin as reference protein, did not reveal significant differences among the three lung samples taken at different developmental stages (Figure 1(b)).

3.2. PDE5 Immunohistochemistry. With all the techniques employed (Bouin or Methacarn fixations, microwave treatment against nonmicrowave treatment, standard or amplified ABC methods), at every stage we examined, PDE5 immunoreactivity was restricted to the cytoplasmic compartment of specific cell types. Sections incubated with preimmune serum instead of the primary antibody, as well as those incubated with the antibody pre-adsorbed with the peptide utilised as an immunogen, were free of labelling.

In all the examined developmental stages, the epithelium of the airways was unlabelled, while a mild staining was found in the smooth muscle of specific parts of the 


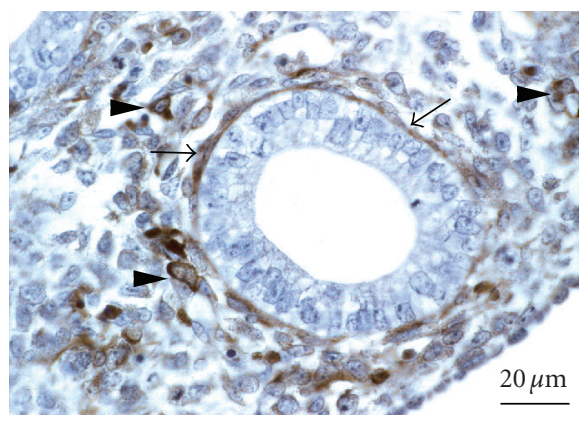

(a)

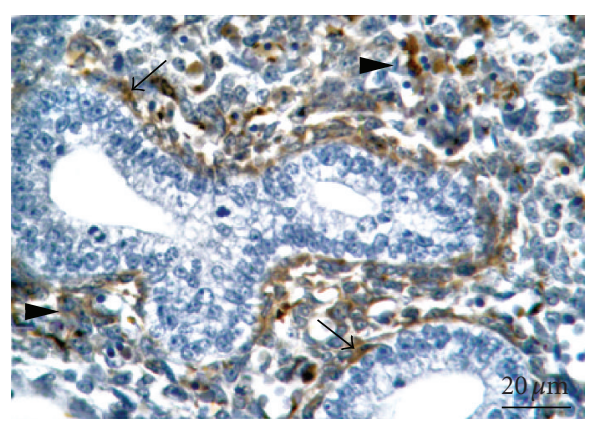

(b)

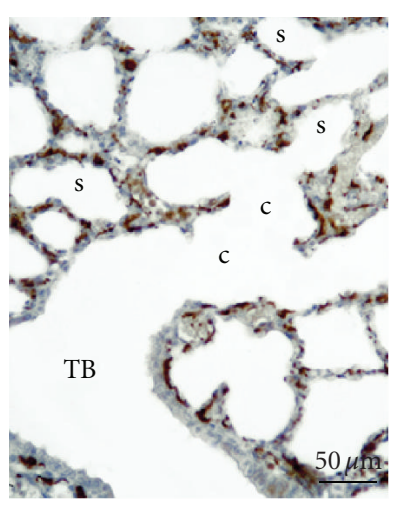

(c)

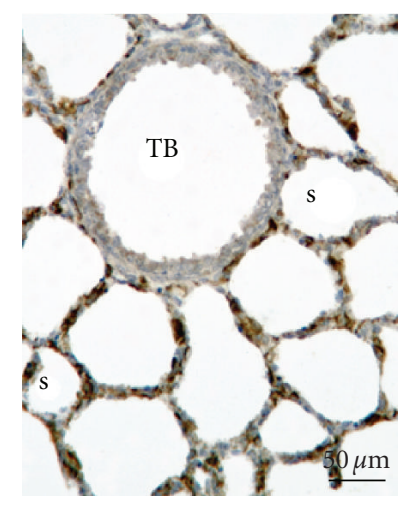

(d)

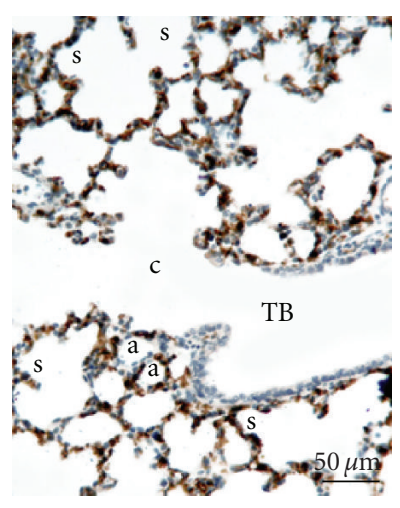

(e)

FIgURE 2: Rat lung. Bouin fixation. PDE5 immunohistochemistry carried out via the amplified ABC method on microwave treated sections. Haematoxylin counterstaining. (a) E15.5, (b) E17.5, (c) P3, (d) P7, (e) P14. s: saccule; a: alveolus; c: canalicular portion of the respiratory space; TB terminal bronchiole; LB larger bronchiole. ((a), (b)) Bar $20 \mu \mathrm{m}$; ((c), (d), (e)) Bar $50 \mu \mathrm{m}$. ((a), (b)) positivity is restricted to the cytoplasm of several cells, the majority of which are scattered in the stroma (arrowheads), while some are closely apposed to the respiratory tubule (arrows). The tubular epithelium is unlabelled. ((c), (d), (e)) labelling is restricted to the distal parenchyma, including sacculi, alveoli, and canalicular portions of respiratory spaces. The epithelium of terminal bronchioles is unstained.

respiratory tree (e.g., major airways in embryos, larger bronchioles in suckling rats). Vascular myocytes were very mildly labelled, and their staining intensity changed with respect to the fixation and incubation conditions, reaching total negativity in Methacarn-fixed specimens.

Both in pre- and in postnatal lungs, the heaviest PDE5positivity was shown in cells located in the pulmonary stroma. In embryos, both at pseudoglandular (E15.5) and at canalicular (E17.5) phases of lung development (Figures 2(a) and 2(b)), these strongly labelled cells were numerous and randomly distributed, with only some closely adhering to the epithelial wall.

In suckling rats (Figures 2(c), 2(d), and 2(e)), heavily labelled stromal cells were especially abundant in the walls of distal respiratory spaces (sacculi and alveoli depending on developmental stage); concerning larger airways, a mild staining was present in the muscular layer of larger bronchioles, while terminal bronchioles appeared unlabelled. Neither number nor position of PDE5-expressing cells remarkably changed among the examined developmental stages.
3.3. Immunohistochemistry of Cytoskeletal Proteins. In all the examined specimens, independently from the different fixation and incubation conditions, at every examined stage the immunoreactivity for total actin, $\alpha$-SMA, and desmin was restricted to the cytoplasmic compartment of specific cell types; all control sections were free of labelling. Concerning the strength of labelling, the best results were obtained with Methacarn-fixed, nonmicrowave-treated specimens.

Throughout the examined postnatal development the cytoskeletal markers were immunolocalised in muscle cells belonging to bronchial, bronchiolar, and vessel walls as well as in those underlying the epithelia in the canalicular portions of the respiratory spaces; epithelia were always unlabelled, while a specific labelling was additionally found in the cytoplasmic compartment of many cells of the intersaccular walls. All control sections were free of labelling.

Concerning the distribution of positivity in the intersaccular wall, at 3, 7, and 14 days of postnatal development: (i) total actinexpressing cells were relatively few and randomly distributed inside the interstitium; (ii) desmin-containing as well as $\alpha$-SMA-positive cells were sensibly more numerous; moreover, they were preferentially found in close proximity 


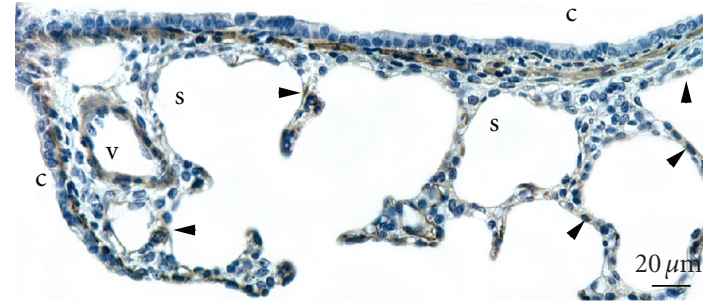

(a)

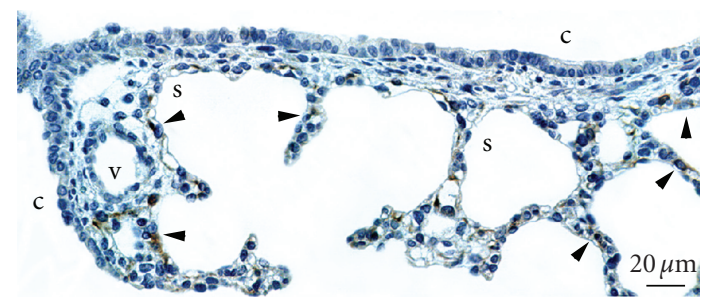

(b)

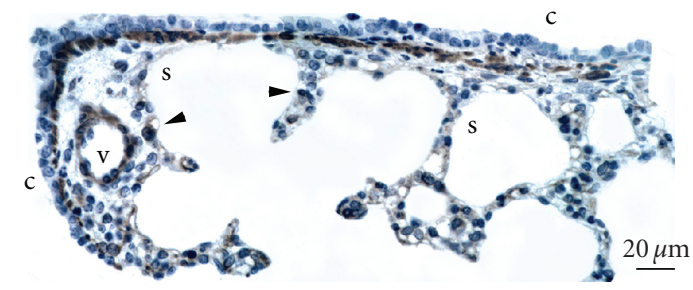

(c)

Figure 3: Rat lungs. Postnatal day 3. Methacarn fixation. Immunolocalisation of different markers, carried out in adjacent sections. Standard ABC method. Haematoxylin counterstaining. s: saccule; c: canalicular portion of respiratory space; v: vessel. Bar $20 \mu \mathrm{m}$. (a) $\alpha$-SMA immunolocalisation. Besides what found in the vascular wall, a strong labelling is found in the myocytes adhering to the epithelium in the canalicular portions of respiratory spaces, as well as in cells located in the intersaccular walls. (b) PDE5 immunolocalisation. The labelling is restricted to the cytoplasm of several stromal cells, located in close proximity with the saccular boundary. The myocytes of the small vessel and of respiratory channels are unstained. (c) desmin immunolocalisation. Both the myocytes in the canalicular portions of respiratory spaces and those belonging to the vessel wall are strongly labelled; moreover few labelled cells are scattered in the intersaccular walls. Arrows indicate some $\alpha$-SMA- or desmin-containing PDE5-positive cells.

to the respiratory epithelium, especially on the tip of the intersaccular septa, and around the venules at the junctions of the three septa.

At all the examined stages, the number and distribution of PDE5-expressing cells appeared substantially similar to those of $\alpha$-SMA-containing cells, while the correspondence was weaker with desmin-containing elements. Finally, only rare and randomly located stromal cells showed the contemporary presence of PDE5 and total actin. The developmental stage of P3 was chosen as the most suitable for validating these preliminary results, and serial sections taken from 3 day-old animals were therefore submitted the immunolocalisation of PDE5, $\alpha$-SMA, and desmin. Figure 3 shows a representative field, where several PDE5-expressing cells, located in the saccular wall, are found to correspond to $\alpha$ SMA-containing elements, while a lower number is found to express desmin; fewer cells appear to express all three markers at the same time.

\section{Discussion}

PDE5-immunolocalization experiments revealed that in preand postnatal rat lungs stromal cells located in the interstitium between the respiratory units mainly expressed the enzyme. More in particular, during pseudoglandular and canalicular phases of prenatal lung development, PDE5expressing cells showed a preferential position close to the tubular epithelium, while during the saccular phase of postnatal lung development they were exclusively found in the wall of distal respiratory spaces (canaliculi, sacculi, alveoli).

Concerning lung airways and vessels in the respiratory tree, PDE5 immunoreactivity was always absent in epithelium and hardly detectable in muscle of larger bronchioles, while vascular myocytes were very mildly labelled and their staining intensity changed with respect to fixation and incubation conditions.

Discrepancies between our results and those reported by other authors who found stronger PDE5 expression in vascular walls during perinatal development $[11,12]$ might be due to differences in the experimental method (in situ hybridization instead of immunohistochemistry) and adopted species (sheep instead of rats).

The high level of PDE5 expression shown in suckling rat lungs by nonvascular cells of distal parenchyma supports the previously suggested idea [12] that in perinatal lung the NO/cGMP signal transduction system might play key roles not only in the regulation of vascular resistance but more generally in tissue remodelling. In immature rodent lungs the angiogenic factor VEGF is known to induce endothelial proliferation and differentiation through binding to Flk-1 [29], highly expressed by endothelial cells closely apposed to the developing epithelium $[30,31]$. According to results obtained in other experimental models [32, 33], we argue that in immature lungs, Flk-1-bound VEGF stimulates endothelial nitric oxide synthase, with consequent nitric oxide production. NO/cGMP system and cGMP modulation, therefore, appear to be crucial steps in pulmonary angiogenesis.

Concerning the cell types that specifically express PDE5 in neonatal rat lungs, we found that many of them also contain $\alpha$-SMA, while some expressing desmin; on the other hand only few cells express all the three markers at the same time. According to recent literature [34], the $\alpha$ $\mathrm{SMA}+/$ desmin- cells mainly include interstitial myofibroblasts, with a contribute of transitional pericytes bound to preand postcapillary microvascular segments [35, 36], while the $\alpha$-SMA-/desmin + cells are presumed to be interstitial lipofibroblasts.

It is worth reminding that $\alpha$-SMA-containing myofibroblasts, which in adult lung are only detected during idiopathic or bleomycin-induced fibrosis $[37,38]$, in perinatal 
development show increased $\alpha$-SMA expression and collagen synthesis, together with cytoskeletal reorganization, and are presumed crucial for adaptation to extra uterine life [39].

On the basis of our data concerning PDE5 expression in myofibroblasts and pericytes and in agreement with results obtained in liver and kidney samples (in which the nonselective phosphodiesterase inhibitors pentoxifylline and 3 -isobutyl-1-methylxanthine were found to reduce both proliferation rate and collagen secretion of $\alpha$-SMA-expressing myofibroblasts [40-42]), we argue that in neonatal mammalian lung the NO/cGMP signal transduction system, besides being involved in vessel maturation, influences homeostasis and fibrogenic activity of myofibroblasts.

Structural and functional modifications of myofibroblasts and pericytes, which are both responsible for the tensile fine tuning of capillaries and compliance of interairspace walls $[43,44]$, might constitute the basis for the alterations in extracellular matrix deposition, septal elongation and alveolar maturation found, for example, in hyperoxia-induced pulmonary perinatal hypertension. Interestingly, in this experimental condition sildenafil was found to increase lung capillary density and to preserve alveolar growth [17]. In conclusion the possible effects of PDE5 inhibitors on different pulmonary cell types should be accurately investigated, in order to better utilise these substances as therapeutic agents in neonatal chronic lung diseases characterised by excess matrix deposition.

\section{Abbreviations}

PDE5: cGMP-binding cGMP-specific phosphodiesterase. a-SMA: a-smooth muscle actin.

\section{References}

[1] S. H. Soderling and J. A. Beavo, "Regulation of cAMP and cGMP signaling: new phosphodiesterases and new functions," Current Opinion in Cell Biology, vol. 12, no. 2, pp. 174-179, 2000.

[2] T. M. Lincoln, C. L. Hall, C. Park, and J. D. Corbin, "Guanosine 3' : 5' cyclic monophosphate binding proteins in rat tissues," Proceedings of the National Academy of Sciences of the United States of America, vol. 73, no. 8, pp. 2559-2563, 1976.

[3] J. F. Coquil, G. Brunelle, and J. Guedon, "Occurrence of the methylisobutylxanthine-stimulated cyclic GMP binding protein in various rat tissues," Biochemical and Biophysical Research Communications, vol. 127, no. 1, pp. 226-231, 1985.

[4] J. D. Corbin, A. Beasley, M. A. Blount, and S. H. Francis, "High lung PDE5: a strong basis for treating pulmonary hypertension with PDE5 inhibitors," Biochemical and Biophysical Research Communications, vol. 334, no. 3, pp. 930-938, 2005.

[5] A. Sebkhi, J. W. Strange, S. C. Phillips, J. Wharton, and M. R. Wilkins, "Phosphodiesterase type 5 as a target for the treatment of hypoxia-induced pulmonary hypertension," Circulation, vol. 107, no. 25, pp. 3230-3235, 2003.

[6] M. R. Maclean, E. D. Johnston, K. M. Mcculloch, L. Pooley, M. D. Houslay, and G. Sweeney, "Phosphodiesterase isoforms in the pulmonary arterial circulation of the rat: changes in pulmonary hypertension," Journal of Pharmacology and Experimental Therapeutics, vol. 283, no. 2, pp. 619-624, 1997.
[7] O. Pauvert, S. Bonnet, E. Rousseau, R. Marthan, and J.-P. Savineau, "Sildenafil alters calcium signaling and vascular tone in pulmonary arteries from chronically hypoxic rats," American Journal of Physiology, vol. 287, no. 3, pp. L577-L583, 2004.

[8] M. K. Steiner, I. R. Preston, J. R. Klinger, and N. S. Hill, "Pulmonary hypertension: inhaled nitric oxide, sildenafil and natriuretic peptides," Current Opinion in Pharmacology, vol. 5, no. 3, pp. 245-250, 2005.

[9] N. Kawai, D. B. Bloch, G. Filippov, et al., "Constitutive endothelial nitric oxide synthase gene expression is regulated during lung development," American Journal of Physiology, vol. 268, no. 4, pp. L589-L595, 1995.

[10] K. D. Bloch, G. Filippov, L. S. Sanchez, M. Nakane, and S. M. de La Monte, "Pulmonary soluble guanylate cyclase, a nitric oxide receptor, is increased during the perinatal period," American Journal of Physiology, vol. 272, no. 3, pp. L400-L406, 1997.

[11] K. A. Hanson, F. Burns, S. D. Rybalkin, J. W. Miller, J. Beavo, and W. R. Clarke, "Developmental changes in lung cGMP phosphodiesterase-5 activity, protein, and message," American Journal of Respiratory and Critical Care Medicine, vol. 158, no. 1, pp. 279-288, 1998.

[12] L. S. Sanchez, S. M. de la Monte, G. Filippov, R. C. Jones, W. M. Zapol, and K. D. Bloch, "Cyclic-GMP-binding, cyclic-GMPspecific phosphodiesterase (PDE5) gene expression is regulated during rat pulmonary development," Pediatric Research, vol. 43, no. 2, pp. 163-168, 1998.

[13] S. M. Black, L. S. Sanchez, E. Mata-Greenwood, J. M. Bekker, R. H. Steinhorn, and J. R. Fineman, "sGC and PDE5 are elevated in lambs with increased pulmonary blood flow and pulmonary hypertension," American Journal of Physiology, vol. 281, no. 5, pp. L1051-L1057, 2001.

[14] K. A. Hanson, J. W. Ziegler, S. D. Rybalkin, J. W. Miller, S. H. Abman, and W. R. Clarke, "Chronic pulmonary hypertension increases fetal lung cGMP phosphodiesterase activity," American Journal of Physiology, vol. 275, no. 5, pp. L931-L941, 1998.

[15] J. Weimann, R. Ullrich, J. Hromi, et al., "Sildenafil is a pulmonary vasodilator in awake lambs with acute pulmonary hypertension," Anesthesiology, vol. 92, no. 6, pp. 1702-1712, 2000.

[16] F. Ichinose, J. Erana-Garcia, J. Hromi, et al., "Nebulized sildenafil is a selective pulmonary vasodilator in lambs with acute pulmonary hypertension," Critical Care Medicine, vol. 29, no. 5, pp. 1000-1005, 2001.

[17] F. Ladha, S. Bonnet, F. Eaton, K. Hashimoto, G. Korbutt, and B. Thébaud, "Sildenafil improves alveolar growth and pulmonary hypertension in hyperoxia-induced lung injury," American Journal of Respiratory and Critical Care Medicine, vol. 172, no. 6, pp. 750-756, 2005.

[18] J. N. Travadi and S. K. Patole, "Phosphodiesterase inhibitors for persistent pulmonary hypertension of the newborn: a review," Pediatric Pulmonology, vol. 36, no. 6, pp. 529-535, 2003.

[19] J. Kotera, N. Yanaka, K. Fujishige, et al., "Expression of rat cGMP-binding cGMP-specific phosphodiesterase mRNA in Purkinje cell layers during postnatal neuronal development," European Journal of Biochemistry, vol. 249, no. 2, pp. 434-442, 1997.

[20] J. Kotera, K. Fujishige, and K. Omori, "Immunohistochemical localization of cGMP-binding cGMP-specific phosphodiesterase (PDE5) in rat tissues," Journal of Histochemistry and Cytochemistry, vol. 48, no. 5, pp. 685-693, 2000. 
[21] D. Giordano, M. E. De Stefano, G. Citro, A. Modica, and M. Giorgi, "Expression of cGMP-binding cGMP-specific phosphodiesterase (PDE5) in mouse tissues and cell lines using an antibody against the enzyme amino-terminal domain," Biochimica et Biophysica Acta, vol. 1539, no. 1-2, pp. 16-27, 2001.

[22] J. Wharton, J. W. Strange, G. M. O. Møller, et al., "Antiproliferative effects of phosphodiesterase type 5 inhibition in human pulmonary artery cells," American Journal of Respiratory and Critical Care Medicine, vol. 172, no. 1, pp. 105-113, 2005.

[23] K. N. Farrow, B. S. Groh, P. T. Schumacker, et al., "Hyperoxia increases phosphodiesterase 5 expression and activity in ovine fetal pulmonary artery smooth muscle cells," Circulation Research, vol. 102, no. 2, pp. 226-233, 2008.

[24] J. C. Adams, "Biotin amplification of biotin and horseradish peroxidase signals in histochemical stains," Journal of Histochemistry and Cytochemistry, vol. 40, no. 10, pp. 1457-1463, 1992.

[25] C. S. Lin, A. Lau, R. Tu, and T. F. Lue, "Expression of three isoforms of cGMP-binding cGMP-specific phosphodiesterase (PDE5) in human penile cavernosum," Biochemical and Biophysical Research Communications, vol. 268, pp. 628-635, 2000.

[26] O. Lowry, N. J. Rosembrough, A. R. Farr, and R. J. Randall, "Protein measurement with the folin phenol reagent," Journal of Biological Chemistry, vol. 193, pp. 265-275, 1951.

[27] U. K. Laemmli, "Cleavage of structural proteins during the assembly of the head of bacteriophage T4," Nature, vol. 227, no. 5259, pp. 680-685, 1970.

[28] H. Towbin, T. Staehelin, and J. Gordon, "Electrophoretic transfer of proteins from polyacrylamide gels to nitrocellulose sheets: procedure and some applications," Proceedings of the National Academy of Sciences of the United States of America, vol. 76, no. 9, pp. 4350-4354, 1979.

[29] F. Shalaby, J. Rossant, T. P. Yamaguchi, et al., "Failure of bloodisland formation and vasculogenesis in Flk-1-deficient mice," Nature, vol. 376, no. 6535, pp. 62-66, 1995.

[30] A. J. Bhatt, S. B. Amin, P. R. Chess, R. H. Watkins, and W. M. Maniscalco, "Expression of vascular endothelial growth factor and Flk-1 in developing and glucocorticoid-treated mouse lung," Pediatric Research, vol. 47, no. 5, pp. 606-613, 2000.

[31] Y.-S. Ng, R. Rohan, M. E. Sunday, D. E. Demello, and P. A. D'Amore, "Differential expression of VEGF isoforms in mouse during development and in the adult," Developmental Dynamics, vol. 220, no. 2, pp. 112-121, 2001.

[32] B.-Q. Shen, D. Y. Lee, and T. F. Zioncheck, "Vascular endothelial growth factor governs endothelial nitric-oxide synthase expression via a KDR/Flk-1 receptor and a protein kinase C signaling pathway," Journal of Biological Chemistry, vol. 274, no. 46, pp. 33057-33063, 1999.

[33] D. Fukumura, T. Gohongi, A. Kadambi, et al., "Predominant role of endothelial nitric oxide synthase in vascular endothelial growth factor-induced angiogenesis and vascular permeability," Proceedings of the National Academy of Sciences of the United States of America, vol. 98, no. 5, pp. 2604-2609, 2001.

[34] M. Yamada, H. Kurihara, K. Kinoshita, and T. Sakai, "Temporal expression of alpha-smooth muscle actin and drebrin in septal interstitial cells during alveolar maturation," Journal of Histochemistry and Cytochemistry, vol. 53, no. 6, pp. 735-744, 2005.

[35] V. Nehls and D. Drenckhahn, "Heterogeneity of microvascular pericytes for smooth muscle type alpha-actin," The Journal of Cell Biology, vol. 113, pp. 147-154, 1991.
[36] Y. Kapanci, C. Ribaux, C. Chaponnier, and G. Gabbiani, "Cytoskeletal features of alveolar myofibroblasts and pericytes in normal human and rat lung," Journal of Histochemistry and Cytochemistry, vol. 40, no. 12, pp. 1955-1963, 1992.

[37] Y. Kapanci, A. Desmouliere, J.-C. Pache, M. Redard, and G. Gabbiani, "Cytoskeletal protein modulation in pulmonary alveolar myofibroblasts during idiopathic pulmonary fibrosis: possible role of transforming growth factor beta and tumor necrosis factor alpha," American Journal of Respiratory and Critical Care Medicine, vol. 152, no. 6, pp. 2163-2169, 1995.

[38] H.-Y. Zhang, M. Gharaee-Kermani, K. Zhang, S. Karmiol, and S. H. Phan, "Lung fibroblast $\alpha$-smooth muscle actin expression and contractile phenotype in bleomycin-induced pulmonary fibrosis," American Journal of Pathology, vol. 148, no. 2, pp. 527-537, 1996.

[39] K. Jostarndt-Fögen, V. Djonov, and A. Draeger, "Expression of smooth muscle markers in the developing murine lung: potential contractile properties and lineal descent," Histochemistry and Cell Biology, vol. 110, no. 3, pp. 273-284, 1998.

[40] E. Shimizu, Y. Kobayashi, Y. Oki, T. Kawasaki, T. Yoshimi, and H. Nakamura, "OPC-13013, a cyclic nucleotide phosphodiesterase type III inhibitor, inhibits cell proliferation and transdifferentiation of cultured rat hepatic stellate cells," Life Sciences, vol. 64, no. 23, pp. 2081-2088, 1999.

[41] T. D. Hewitson, M. Martic, K. J. Kelynack, E. Pedagogos, and G. J. Becker, "Pentoxifylline reduces in vitro renal myofibroblast proliferation and collagen secretion," American Journal of Nephrology, vol. 20, no. 1, pp. 82-88, 2000.

[42] D. Schuppan and Y. Porov, "Hepatic fibrosis: from bench to bedside," Journal of Gastroenterology and Hepatology, vol. 17, supplement 3, pp. S300-S305, 2002.

[43] Y. Kapanci and G. Gabbiani, "Contractile cells in pulmonary alveolar tissue," in The Lung: Scientific Foundations, R. G. Crystal, J. B. West, E. R. Weibel, and P. J. Barnes, Eds., pp. 697707, Lippincott-Raven, Philadelphia, Pa, USA, 1997.

[44] E. R. Weibel and R. G. Crystal, "Structural organization of the pulmonary interstitium," in The Lung: Scientific Foundations, R. G. Crystal, J. B. West, E. R. Weibel, and P. J. Barnes, Eds., pp. 685-695, Lippincott-Raven, Philadelphia, Pa, USA, 1997. 

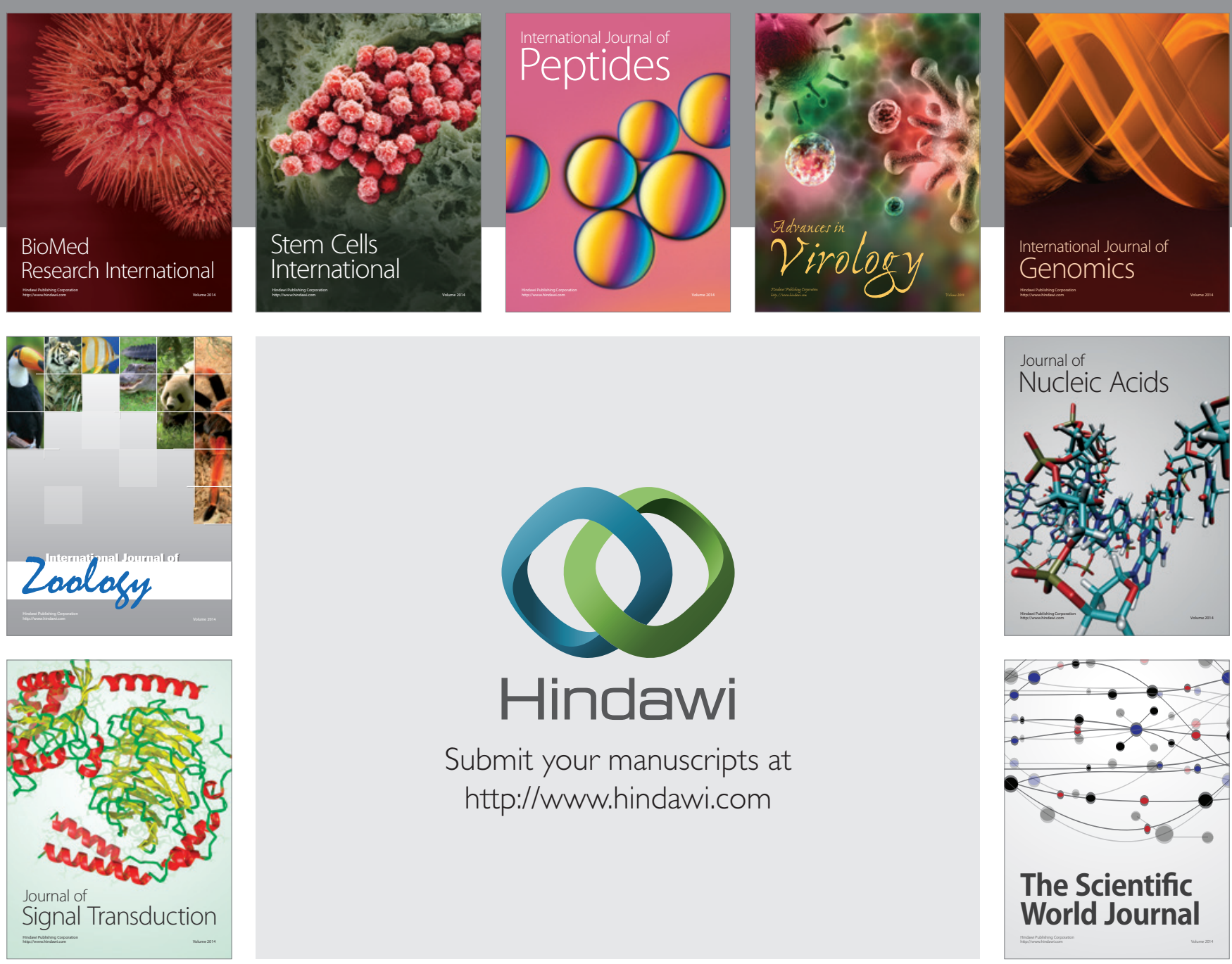

Submit your manuscripts at

http://www.hindawi.com
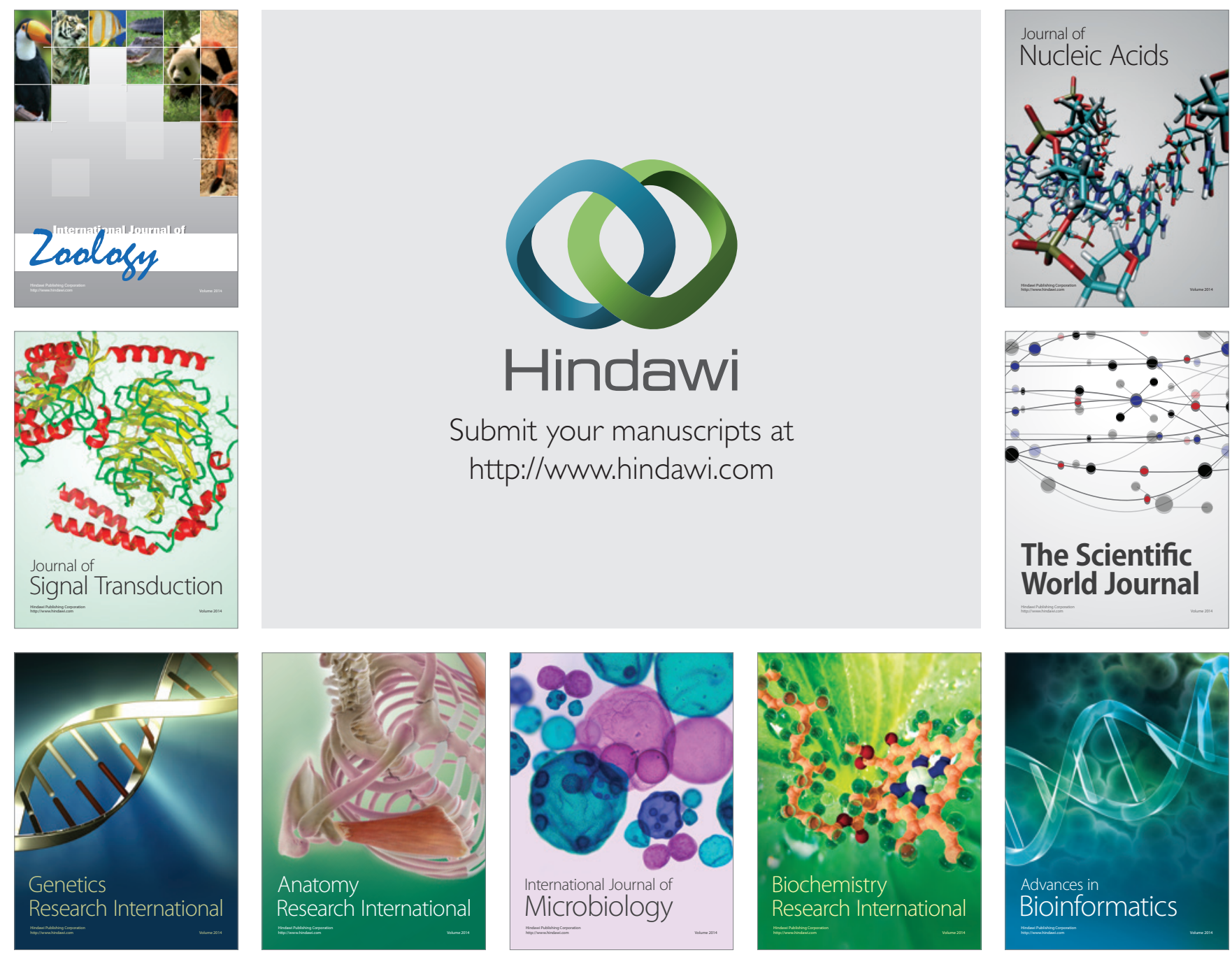

The Scientific World Journal
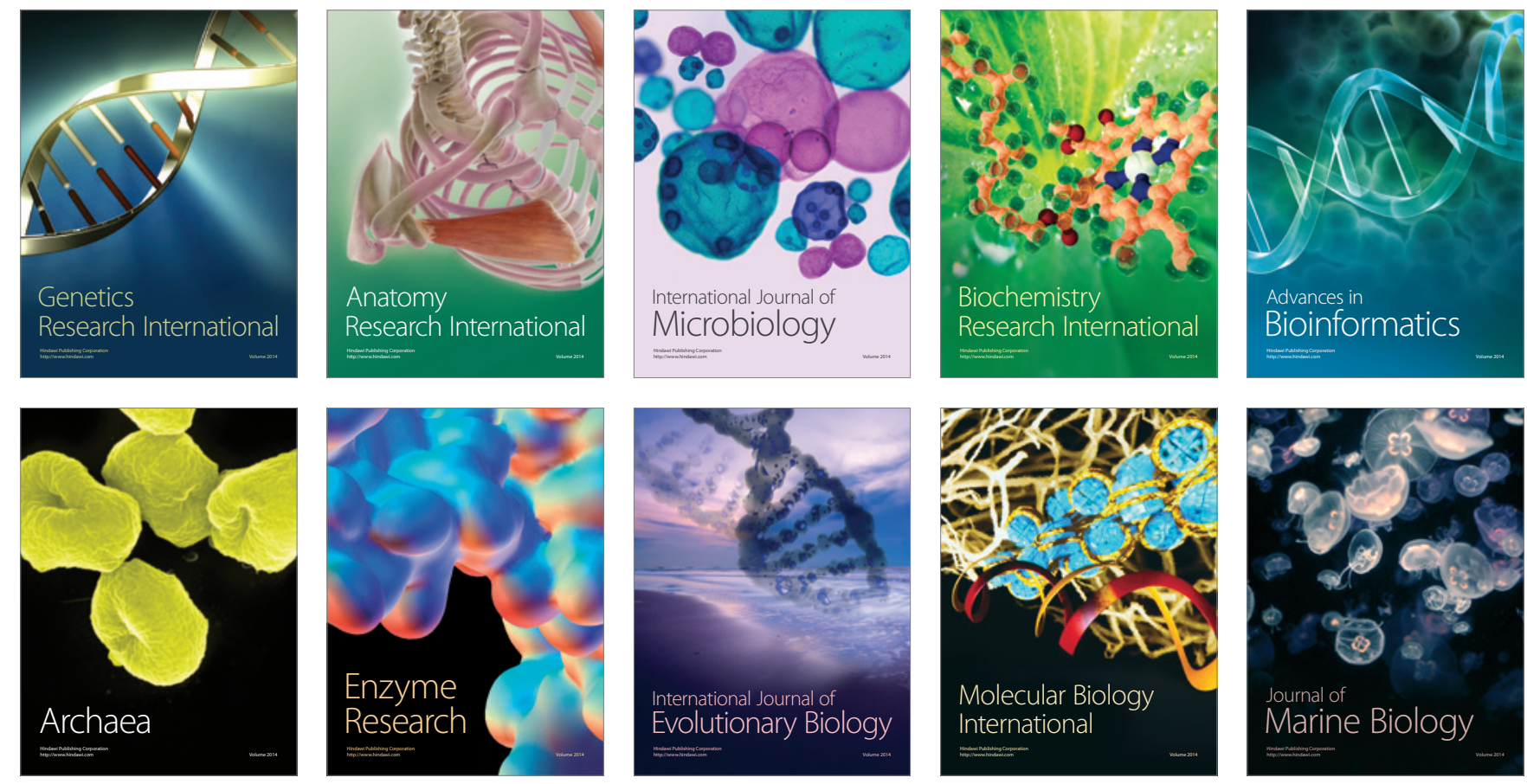